\title{
APLICAÇÃO DE ELETRORRESISTIVIDADE EM SEDIMENTOS PALEOZÓICOS E MESOZÓICOS DO ESTADO DE SÃO PAULO
}

\author{
NÉLSON ELLERT*
}

ABSTRACT In the State of São Paulo, the water wells are mostly concentrated in rocks of the Paraná Basin. 'Therefore geophysical prospecting was employed to determine its applicability in solving geologic and ground-water problems. There was also the intention to verify: how a "geophysical stratigraphy" corresponds with the geologic stratigraphy; if there is a correlation between lateral variation of resistivity and water production in the Tubarão Group sediments.

The conclusions are:

- it seems that it is possible to estimate, with regard to the resistivity of the rocks, the production of a well in the Tubarão Group;

- the Botucatu Sandstone, when saturated of water, has a resistivity of about $30 \mathrm{ohm} \cdot \mathrm{m}$. The position of the water level and the thickness of the Sandstone layer are easily determined;

- the thickness of the basalt is not difficult to determine. When there are more than one flow, a strong "eletrical anisotrophy" may occur;

- the saturated Bauru Sandstone has a resistivity of about $18 \mathrm{ohm} \cdot \mathrm{m}$ its thickness and the position of the water level can be determined.

INTRODUçÃo A aplicação de 'métodos elétricos de prospecção com a finalidade de procurar solucionar problemas geológicos e geo-hidrogeológicos é possível porquanto é ampla a gama de variação da resistividade das rochas.

Para a execução das sondagens elétricas (arranjo Schlumberger) foi utilizada como fonte de corrente um gerador de corrente contínua de $2 \mathrm{~kW} / 500 \mathrm{~V}$. As medidas de diferença de potencial entre os elétrodos $M$ e $N$ foram realizadas por meio de um potenciômetro, segundo o processo da compensação.

Os trabalhos de campo, realizados graças ao auxílio concedido pela Fundação de Amparo à Pesquisa do Estado de São Paulo, foram efetuados nas cidades de Campinas, Itu, Sorocaba, Bálsamo, Cerquilho, São Carlos, Boituva e Araraquara. Essas cidades foram escolhidas de modo a permitir estudar as características elétricas das sequiências lito-estratigráficas:

\author{
Grupo Tubarão (Permo-carbonífero) \\ Embasamento cristalino \\ Sill de diabásio \\ Grupo Tubarão (Permo-carbonífero) \\ Embasamento cristalino \\ Arenito Botucatu (Eocretáceo) \\ Efusivas basálticas (Eocretáceo) \\ Arenito Bauru (Neocretáceo) \\ Efusivas basálticas (Eocretáceo) \\ Efusivas basálticas (Eocretáceo) \\ Arenito Botucatu (Eocretáceo) \\ Arenito Bauru (Neocretáceo) \\ Efusivas basálticas (Eocretáceo) \\ Arenito Botucatu (Eocretáceo)
} USP

* Departamento de Geologia Econômica e Geolsicica Aplicada do Instituto de Geociências da 
Como o trabalho visa à aplicação e os resultados obtidos por eletrorresistividade, em seu procedimento de sondagem elétrica, detalhes teóricos sobre o método não serão aqui tratados.

Análise dos dados de campo a) GRUPO TUBARÃO A fim de verificar o comportamento elétrico de sedimentos pertencentes ao Grupo Tubarão, foram realizados trabalhos de campo em: Campinas (ER-1, ER-2, ER-3, ER-4, ER-5, ER-6), Itu (Caiacatinga, ER-18), Sorocaba (Utinga, ER-17), Porto Feliz (Jupira, ER-15), Boituva (ER-14) e Cerquilho (ER-16).

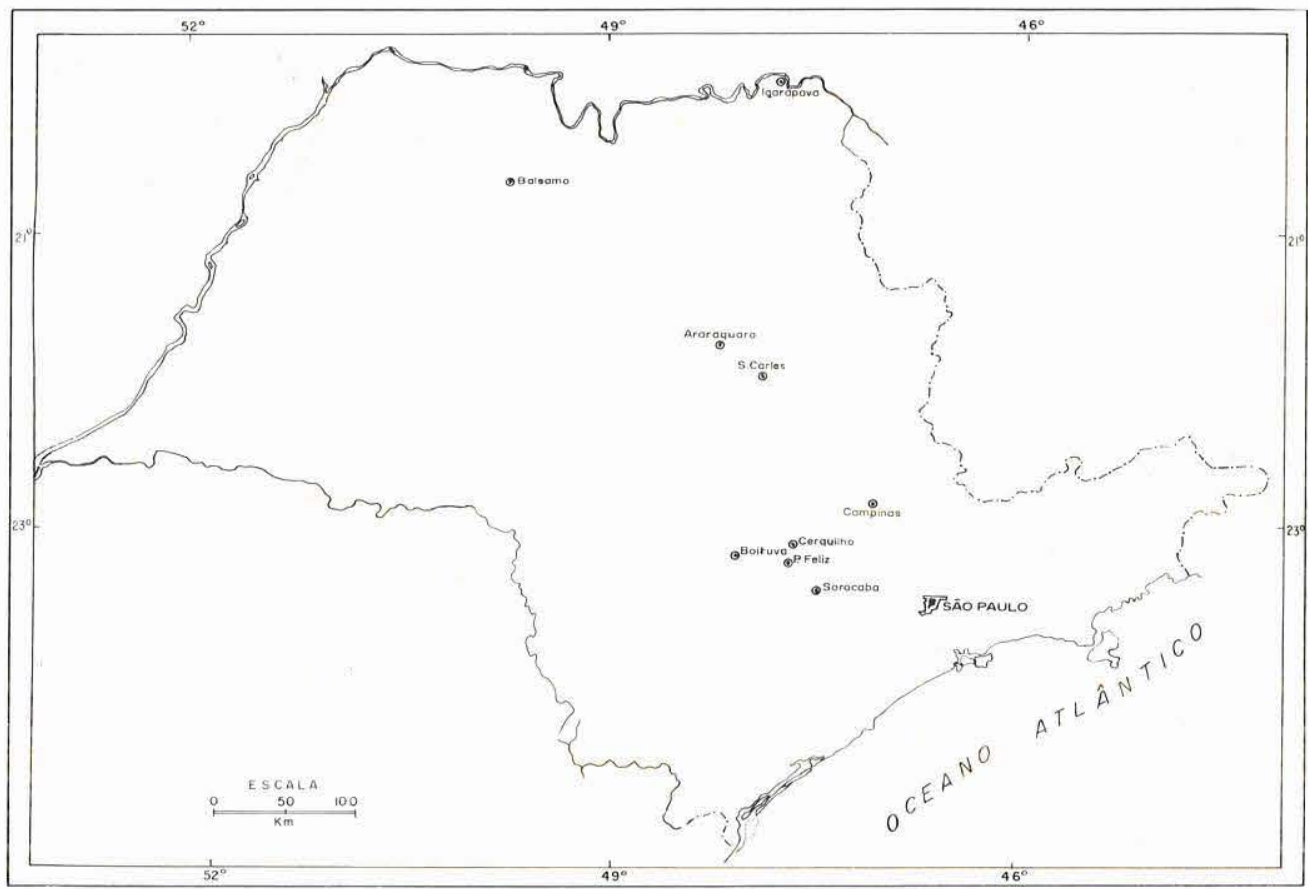

Figura 1 - Mapa de localização das áreas investigadas

1 - Campinas A norte da cidade de Campinas localiza-se a Fazenda Experimental Theodureto de Camargo, da Secretaria da Agricultura do Estado de São Paulo, onde existem 6 poços profundos perfurados pelo Instituto Geográfico e Geológico do Estado de São Paulo.

Nessa região os sedimentos do Grupo Tubarão são constituídos principalmente de argilas, areias, conglomerados e tilitos, com espessuras que variam desde centímetros até alguns metros.

Cinco dos poços estão agrupados numa depressão topográfica e o seu espaçamento não ultrapassa $500 \mathrm{~m}$. Apesar do espaçamento relativamente pequeno entre os poços, é difícil construir-se uma seção geológica baseada nos perfis litológicos. Verifica-se que não existe uma continuidade lateral definida das camadas sedimentares, seja na granulometria, coloração ou no tipo de sedimento.

Com base na interpretação das curvas das sondagens elétricas $E R-1, E R-2, E R-3$ e ER-6 (Fig. 2) obtivemos a seção da Fig. 3. 


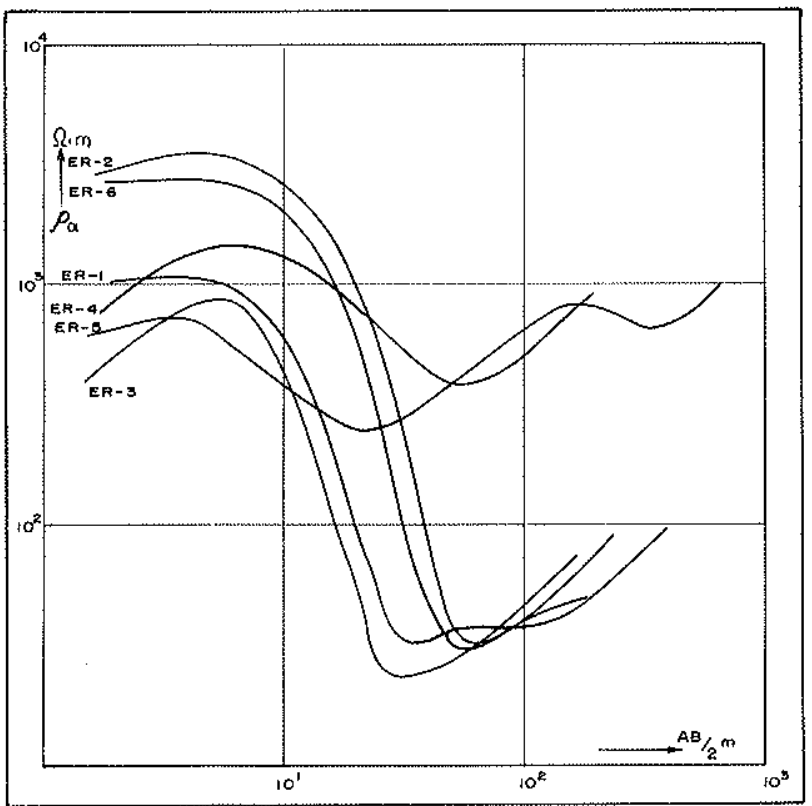

Figura 2 - Curvas de sondagem elétrica $(S E)$

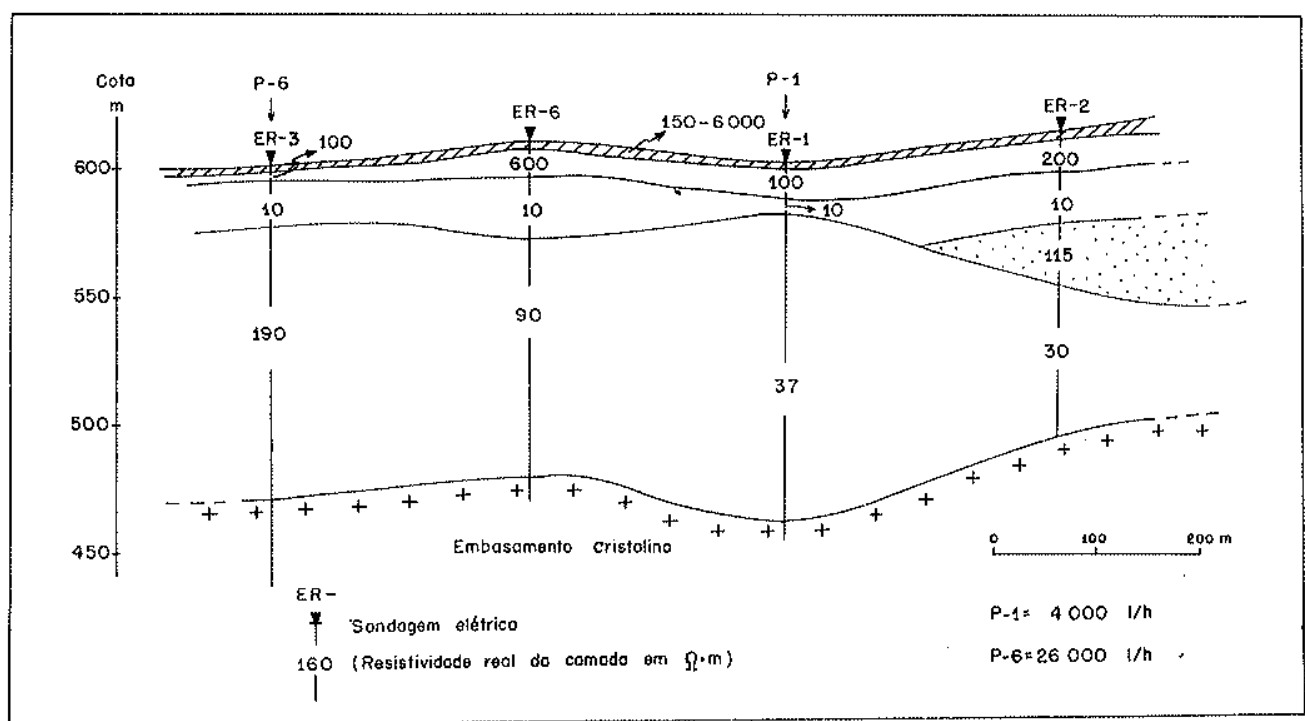

Figura 3 - Seção vertical obtida a partir da interpretação das curvas de sondagem elétrica

Apesar da dificuldade de correlação litológica entre poços próximos, é possível, através da interpretação de sondagens elétricas, reconhecer diferentes horizontes, como mostra a Fig. 3. Essa figura representa uma seqüência de camadas do Grupo Tubarão, onde as resistividades variam de 10 até $6000 \Omega \cdot \mathrm{m}$ (ohm-metro). As camadas de baixo valor de resistividade devem conter grande quantidade de argila, enquanto as outras correspondem a camadas, da superficie do terreno, arenosas e secas. A sondagem elétrica $E R-2$ detectou uma camada com valor de resistividade de $115 \Omega \cdot \mathrm{m}$, a qual deve corresponder a uma lente de arenito intercalada com duas camadas de argila. 
A espessa camada situada imediatamente acima do embasamento cristalino possui resistividades que decrescem de $190 \Omega \cdot \mathrm{m}$ em ER-3 para $30 \Omega \cdot \mathrm{m}$ em ER-2.

A variação lateral ou transversal da resistividade de uma formação geológica (ou camada) é função, entre outros fatores da:

- variação no conteúdo de íons na solução que satura o sedimento;

- variação na granulação;

- variação no conteúdo em argila.

Verificou-se em laboratório que a resistividade da água dos poços $P-1, P-2$ e $P-6$ é praticamente a mesma, da ordem de $40 \Omega \cdot \mathrm{m}$, sugerindo idêntico teor em sais dissolvidos. Pode-se, assim, admitir que a variação na resistividade dessa camada basal é função do conteúdo em argila ou diminuição na granulação do sedimento. Como variações no conteúdo em argila podem alterar as condições de porosidade e permeabilidade, ocorrerão variações na vazão dos poços.

Na Fig. 3 estão representados também os poços $P$-1 e $P$-6. O poço $P$-1 apresenta uma vazão de $4,0 \mathrm{~m}^{3} / \mathrm{h}$ e o poço $P-6$ a de $26 \mathrm{~m}^{3} / \mathrm{h}$.

Com base nos dados dessa seção vertical e de vazão, procura-se, pela Fig. 4, correlacionar os valores de resistividade das camadas aqüíferas e a vazão específica.

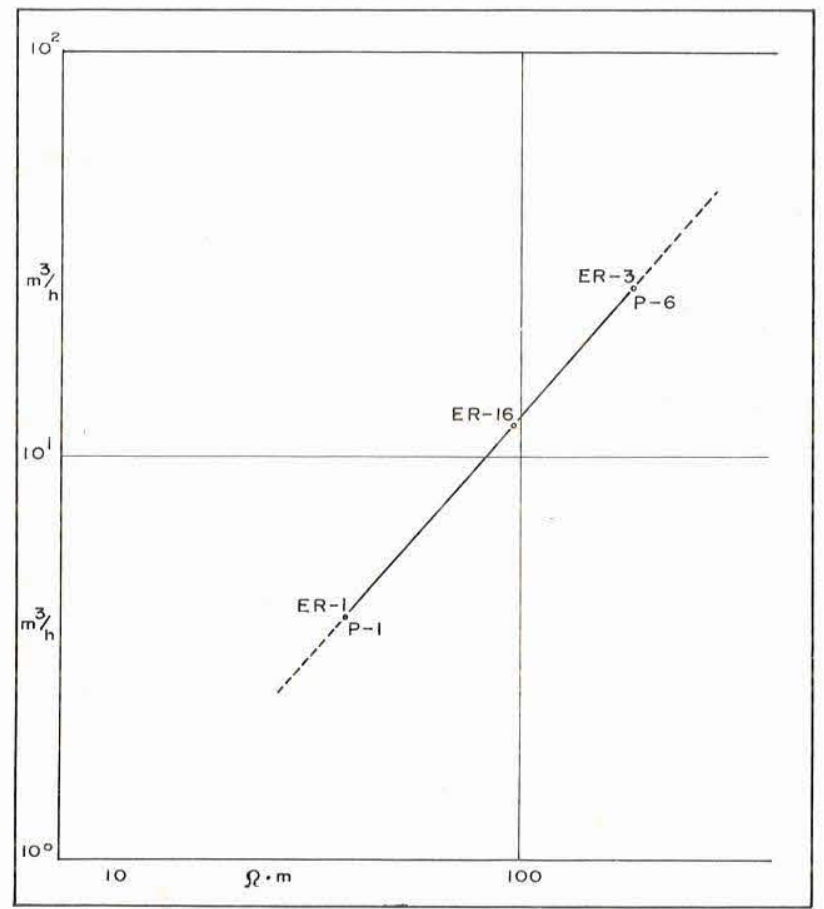

Figura 4 - Gráfico da relação resistividade $\times$ vazão

Como os dados são poucos, essa interpretação tem antes um caráter qualitativo e sua aceitação deve ser feita com certa reserva. Se a resistividade da solução que satura os sedimentos ou o fator de formação de uma camada variar, a reta sofrerá um deslocamento. Em princípio, pode-se admitir que, nos sedimentos do Grupo Tubarão, valores elevados de resistividade, nas áreas próximas à borda da bacia sedimentar, apresentam possibilidades de vazão elevada (superior a $10 \mathrm{~m}^{3} / \mathrm{h}$ ). 


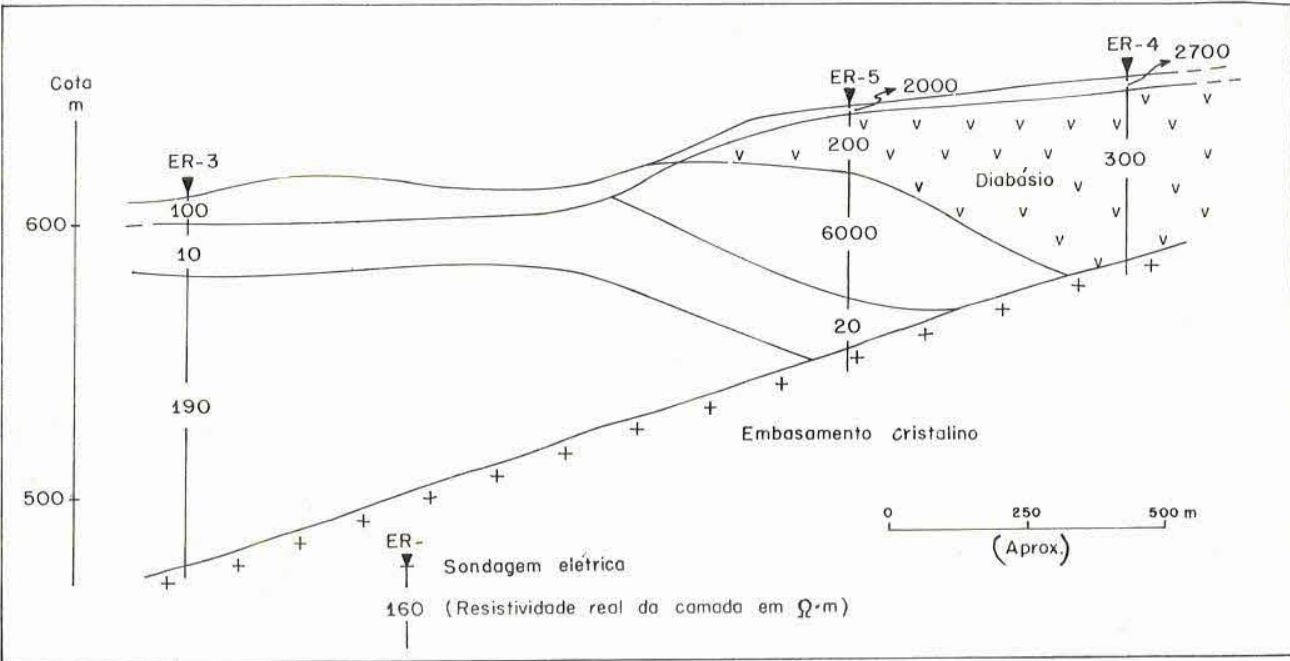

Figura 5 - Seção vertical entre ER-3, ER-4 e ER-5

As sondagens elétricas ER-4 e ER-5 foram executadas em locais onde na superfície do terreno aflora diabásio alterado. Com dados obtidos na interpretação dessas curvas, obtivemos o perfil da Fig. 6.

O valor da resistividade do diabásio é relativamente baixo, devido, talvez, à presença de fendas e diáclases saturadas de água. A parte restante é constituída por sedimentos do Grupo Tubarão. Verifica-se também que o sill de diabásio apresenta um acunhamento na direção de ER-3.

Perfis magnetométricos foram feitos e observou-se que, ao ponto onde começa o solo proveniente da decomposição do diabásio, não corresponde o início da anomalia magnética. Esse fenômeno deve ser produto da intemperização total dessa parte do sill, pois, com o acunhamento, a ação do intemperismo é bem intensa, alterando completamente a susceptibilidade magnética do diabásio.

Durante os trabalhos de campo verificou-se uma ação muito intensa das correntes telúricas. Como os sedimentos possuem resistividade média $\left(\rho_{m}=\frac{\sum m_{i}}{\sum l_{i} / \rho_{i}}\right.$, onde $\sum m_{i}$ é o somatório das espessuras das camadas sedimentares e $\sum \frac{l_{i}}{\rho_{i}}$ o somatório da relação entre a espessura e resistividade das camadas) muito menor que o embasamento cristalino, há uma concentração dessas correntes nas camadas sedimentares na borda da bácia.

A fim de contornar essa dificuldade, procurou-se realizar as medidas com valores de $\overline{\mathrm{MN}}$ maiores que $50 \mathrm{~m}$ na parte da manhã, quando a intensidade destas correntes era relativamente menor.

Outra dificuldade era a alta resistência de contato proveniente da granulação grosseira do material que forma o solo. A uma alta resistência de contato, para uma mesma diferença de potencial entre os elétrodos de corrente $A$ e $B$, corresponde uma baixa intensidade de corrente $I$ que circula pelo terreno. Como $\rho_{a}=K \frac{\Delta V}{I}$, a uma baixa intensidade de corrente $I$, para o mesmo valor $\rho_{a}$ e $K$ corresponde um baixo valor $\Delta V$, medido entre $M$ e $N$. Como a presença de correntes telúricas é praticamente constante, há a necessidade de se obter um valor $\Delta V$ bem maior que o provocado pelas correntes telúricas. Para tal, 
é necessário que a intensidade da corrente $I$ seja elevada. Foi possível obter-se uma diminuição na resistência de contato com o uso de certos artifícios como:

- umedecer com água salgada as vizinhanças dos elétrodos de corrente;

- empregar 3 elétrodos de corrente em cada ponto $A$ e $B$, a partir de $A B / 2$ igual a $50 \mathrm{~m}$, reduzindo de cerca $50 \%$ a resistência de contato;

- enterrar bem os elétrodos no solo (cerca de $1 \mathrm{~m}$ ) até atingir a zona mais úmida.

2 - Sorocaba Na região de Utinga, situada a cerca de $8 \mathrm{~km}$ de Sorocaba, foi realizada a sondagem elétrica $E R-17$ (Fig. 6).

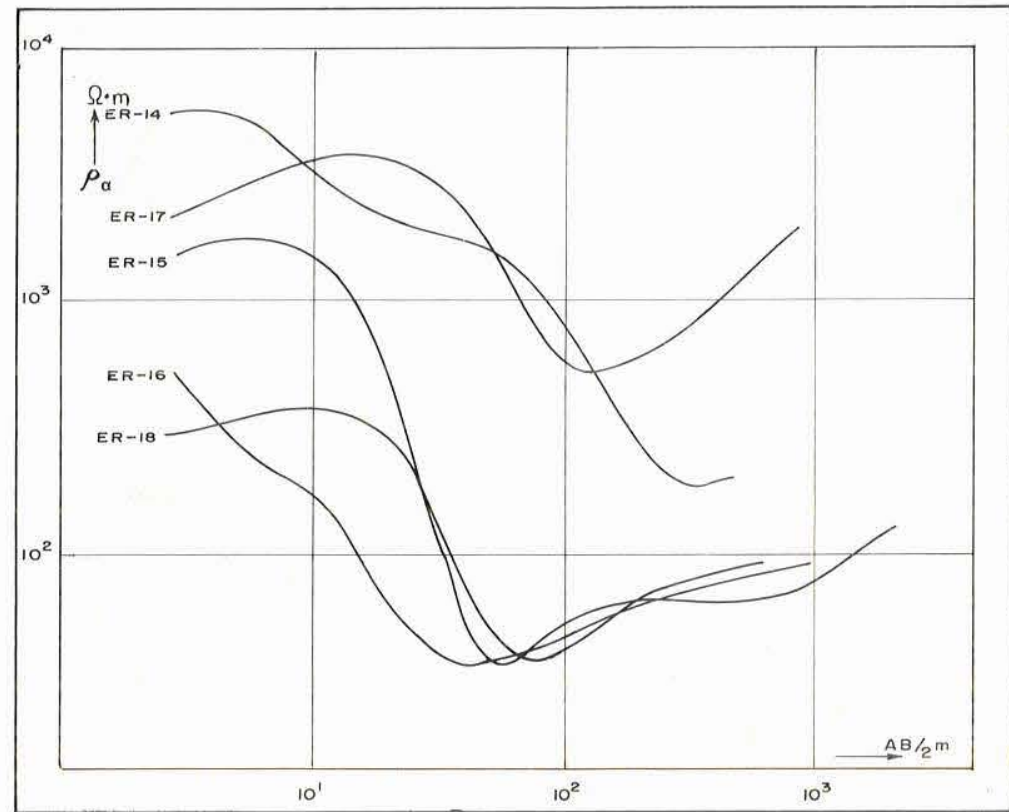

Figura 6 - Curvas de sondagem elétrica

Interpretando-se a curva, obtém-se uma coluna geológica composta de uma série de camadas constituídas por: solo, sedimento não-saturado, sedimento saturado e o embasamento cristalino situado a uma profundidade de aproximadamente $90 \mathrm{~m}$.

A camada situada imediatamente acima do embasamento pode ser interpretada como constituída de arenito grosseiro. Apesar da localidade estar próxima à borda da bacia sedimentar a intensidade das correntes telúricas era bastante reduzida. A resistência de contato foi da ordem de $1700 \Omega$.

3 - Caiacatinga Essa sondagem elétrica ER-18 (Fig. 6), foi feita a uma distância de aproximadamente $20 \mathrm{~km}$ da borda da bacia sedimentar. A interpretação da curva fornece a seguinte coluna:

\begin{tabular}{ccl}
\hline Espessura, $\mathrm{m}$ & Resistividade, $\Omega \cdot \mathrm{m}$ & \multicolumn{1}{c}{ Litologia } \\
\hline \hline 1,3 & 260 & Solo \\
5,0 & 500 & Sedimento não-saturado \\
15,0 & 20 & Sedimento argiloso saturado \\
maior que 300 & 100 & Sedimento arenoso saturado \\
\hline
\end{tabular}


Uma cisterna localizada nas proximidades do ponto de observação apresentava na ocasião o nível d'água a uma profundidade de 7,0 m, o que concorda razoavelmente com os dados obtidos pela sondagem elétrica.

4 - Porto Feliz (Jupira) Nesse local foi executada a sondagem elétrica ER-15 (Fig. 6), que atingiu um espaçamento $A B / 2$ de $1000 \mathrm{~m}$. Observa-se, através da curva, que foi atingido o embasamento cristalino, uma vez que ela apresenta seu trecho final fazendo um ângulo de $45^{\circ}$ com o eixo das ordenadas.

Geologicamente, essa região é constituída por uma delgada cobertura de solo, seguida por um sedimento não-saturado. A partir dos $3,00 \mathrm{~m}$ de profundidade aparece um sedimento argiloso saturado que, após os 10,00 m torna-se arenoso até atingir o embasamento que se situa a uma profundidade aproximada de $590,00 \mathrm{~m}$.

A interpretação de $E R-15$ mostra-nos a presença de uma espessa camada basal com resistividade de $75 \Omega \cdot \mathrm{m}$. A resistência de contato foi da ordem de $2400 \Omega$. Para medidas de resistividades para espaçamentos $A B / 2$ maiores que $600 \mathrm{~m}$, usou-se um espaçamento $M N=80 \mathrm{~m}$, verificando-se a quase ausência de correntes telúricas.

5 - Boituva Essa sondagem elétrica foi realizada numa localidade onde, na superficie, aflora diabásio alterado. A interpretação de ER-14 fornece-nos a seguinte coluna:

\begin{tabular}{ccl}
\hline Espessura, $\mathrm{m}$ & Resistividade, $\Omega \cdot \mathrm{m}$ & \multicolumn{1}{c}{ Litologia } \\
\hline \hline 2,0 & 5300 & Diabásio alterado \\
26,0 & 1800 & Diabásio alterado (?) \\
125,0 & 140 & Sedimento arenoso saturado \\
\hline
\end{tabular}

Verificou-se nessa localidade uma forte intensidade das correntes telúricas. Com o espaçamento $M N=40 \mathrm{~m}$ tornou-se impossível realizar as medidas entre os elétrodos de potencial. Os trabalhos foram interrompidos e, posteriormente, no período noturno, reiniciados, verificando-se um decréscimo de intensidade nas correntes telúricas de cerca 10 vezes.

A resistência de contato, média apesar da superfície do terreno ser argilosa, foi de $9500 \Omega$.

6 - Cerquilho Como na localidade de Capuava de S. Francisco, nos arrebaldes da cidade, foi perfurado um poço pelo I.G.G.S.P., e executou-se a sondagem elétrica (ER-15), de modo a verificar-se a possibilidade de correlação entre os dados geofísicos e geológicos e de vazão do poço. Os dados de resistividade foram relacionados com os de vazão e estão representados na Fig. 5. A coluna "estratigráfica", com base na interpretação, é a seguinte:

\begin{tabular}{crl}
\hline Espessura, $\mathrm{m}$ & Resistividade, $\Omega \cdot \mathrm{m}$ & \multicolumn{1}{c}{ Litologia } \\
\hline \hline 0,6 & 1000 & Solo seco \\
3,2 & 250 & Sedimento arenoso saturado \\
19,0 & 28 & Sedimento argiloso saturado \\
Maior que 250,00 & 95 & Sedimento arenoso saturado \\
\hline
\end{tabular}

b) FORMAÇÃO BAURU, FORMAÇÃO BOTUGATU, DERRAMES BASÁLTICOS Com base nos dados referentes à perfuração de poços profundos no Estado de São Paulo, verificou-se que os melhores aqüíferos são os arenitos pertencentes às Formações Bauru $\mathrm{e}$ Botucatu (Durante et al., 1965). 
Por outro lado, não faltam exemplos de fracassos ocorridos quando se tentou atingir, por meio de sondagens, a camada aqüífera subjacente aos derrames basálticos, sendo suspensa a perfuração quando a espessura da camada basáltica excedeu a metragem prevista, onerando excessivamente a empreitada ou ultrapassando a capacidade da sonda. Em regiões cobertas por derrames basálticos, há casos em que a perfuração do poço foi suspensa quando faltavam, possivelmente, apenas alguns metros para se atingir o arenito aqüífero subjacente, perdendo-se completamente o poço.

Os trabalhos de campo realizados em Araraquara, São Carlos e Bálsamo visaram:

- determinar a resistividade, ou resistividades, das formações sedimentares dos derrames basálticos;

- identificar, a partir da interpretação da curva de eletrorresistividade, a posição da formação geológica mais propícia ao armazenamento de água subterrânea;

- procurar estabelecer a coluna geológica a partir da interpretação das sondagens elétricas.

Para possibilitar melhores resultados foram executadas sondagens elétricas em locais onde existem as seguintes seqüências geológicas:

Arenito Botucatu

Derrame basáltico

ER-19, ER-20

Derrame basáltico

Arenito Botucatu

ER-10, ER-21, ER-23

Arenito Bauru

Derrame basáltico

ER-22, ER-32

Arenito Bauru

Derrame basáltico

Arenito Botucatu

$E R-24$

1) (rrame basáltico

ER-19 Essa sondagem elétrica foi realizada ao longo do Ribeirão do Melo, nas proximidades de São Carlos. Segue-se a sua interpretação.

A região é constituída por uma seqüência de sedimentos modernos que atingem aproximadamente 20 metros de espessura, sob os quais se encontra o Arenito Botucatu. A uma profundidade de 80 metros deve encontrar-se o derrame de basalto.

ER-20 Executada em um local onde a superfície do terreno é constituída por uma camada de areia grossa, solta, seca e bem selecionada. Em razão desses fatores a resistência de contato foi da ordem de $15000 \Omega$. Uma vez que a fonte de corrente empregada foi um gerador de tensão máxima de $500 \mathrm{~V}$, a máxima intensidade de corrente que fluiu pelo solo foi da ordem de $30 \mathrm{~mA}$. Como a parte superficial é constituída por camadas com resistividade de 15000 a $45000 \Omega \cdot \mathrm{m}$ e sob elas existe o Arenito Botucatu saturado com cerca de $30 \Omega \cdot m$ de resistividade, as linhas eqüipotenciais sofrem tal adernamento que a diferença de potencial a ser medida entre $M$ e $N$ torna-se muito pequena, impossibilitando sua determinação.

A interpretação da curva ER-20 nos fornece os dados abaixo:

\begin{tabular}{ccl}
\hline Espessura, $\mathrm{m}$ & Resistividade, $\Omega \cdot \mathrm{m}$ & \multicolumn{1}{c}{ Litologia } \\
\hline \hline 1,0 & 15000 & Areia solta seca \\
5,0 & 45000 & Areia compacta seca \\
$?$ & $30(?)$ & Arenito Botucatu saturado \\
\hline
\end{tabular}




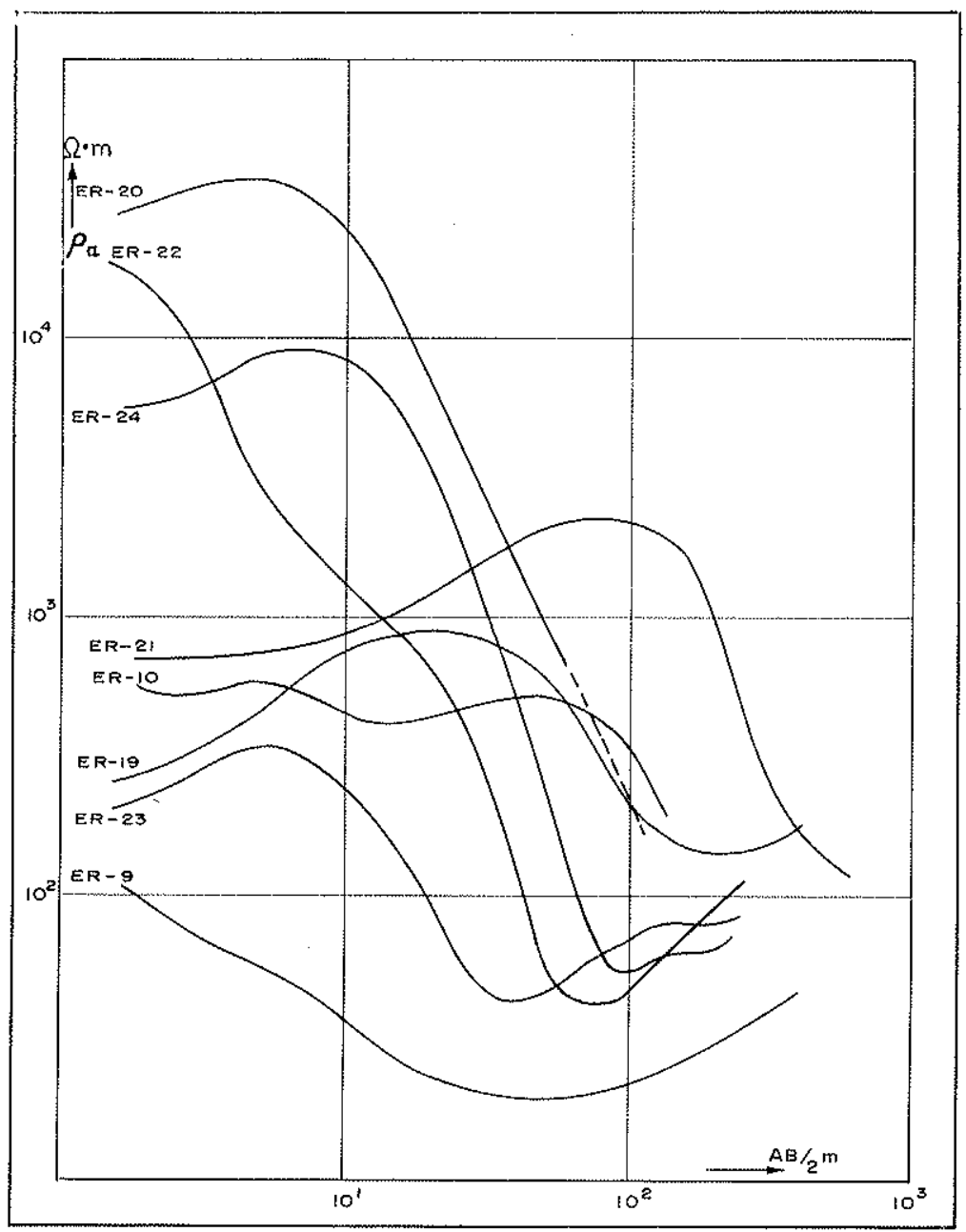

Figura 7 - Curvas de sondagem elétrica $(S E)$

ER-10 Essa sondagem elétrica foi executada às margens do Rio Grande, próximo a cidade de Igarapava. A sequiência geológica nesse local é a seguinte:

Sill de diabásio

Arenito Botucatu

A partir da interpretação da curva obtemos os seguintes dados:

\begin{tabular}{ccl} 
Espessura, $\mathrm{m}$ & Resistividade, $\Omega \cdot \mathrm{m}$ & \multicolumn{1}{c}{ Litologia } \\
\hline 0,7 & 950 & Solo seco \\
0,7 & 230 & Solo úmido \\
2,1 & 920 & Diabásio alterado \\
4,0 & 180 & Diabásio alterado saturado \\
45,0 & 670 & Diabásio fresco \\
& 33 & Arenito Bolucatu saturado
\end{tabular}


Uma sondagem rotativa executada nesse local forneceu o seguinte perfil:

\begin{tabular}{cl}
\hline Espessura, m & \multicolumn{1}{c}{ Litologia } \\
\hline \hline 7,8 & Silte arenoso \\
45,7 & Sill de diabásio \\
& Arenito Botucatu \\
\hline
\end{tabular}

Comparando-se as profundidades, a interpretada e a verificada, para o contato entre o diabásio e o Arenito Botucatu, nota-se que o erro foi inferior a $2 \%$.

ER-21 Essa região é formada por rochas basálticas que capeiam o Arenito Botucatu. Sua interpretação é a seguinte:

\begin{tabular}{ccl}
\hline Espessura, $\mathrm{m}$ & Resistividade, $\Omega \cdot \mathrm{m}$ & \multicolumn{1}{c}{ Litologia } \\
\hline \hline 8,5 & 650 & Solo argiloso \\
43,5 & 5000 & Derrame basáltico \\
& 30 & Arenito Botucatu \\
\hline
\end{tabular}

Num levantamento geológico expedito, verificou-se, por meio de um altímetro, que o contato inferior aflorante entre o basalto e o arenito situa-se $50 \mathrm{~m}$ abaixo da cota do ponto onde foi executada sondagem elétrica.

Apareceu nessa sondagem elétrica uma camada de basalto com resistividade a cerca $5000 \Omega \cdot \mathrm{m}$, ou seja, muito mais elevada do que normalmente. Esse pacote basáltico deve ser produto de uma série de derrames, onde, na zona que separa os derrames sucessivos, desenvolveu-se uma faixa diaclasada e intemperizada de baixa resistividade. Aplicando-se uma corrente elétrica na superfície, essa corrente concentra-se nessas faixas argilosas, aparecendo assim uma condutividade horizontal muito elevada em relação à condutividade vertical, ou seja, uma anisotropia elétrica. Medidas efetuadas na superfície fornecem elevados valores de resistividade.

A resistência de contato média foi da ordem de $1900 \Omega$. Para distâncias $A B / 2$ maiores que $50 \mathrm{~m}$, a resistência de contato caiu para $650 \Omega$, por terem sido utilizados 3 elétrodos de corrente em cada extremidade.

ER-22 Das curvas obtidas para elaboração deste trabalho, essa foi a que apresentou maior gama de variação de valores de resistividade aparente medidas no campo. É a seguinte a sua interpretação:

\begin{tabular}{ccl}
\hline Espessura, $\mathrm{m}$ & Resistividade, $\Omega \cdot \mathrm{m}$ & \multicolumn{1}{c}{ Litologia } \\
\hline \hline 1,3 & 19000 & Camada de solo compacto e seco \\
2,3 & 4000 & Areia seca \\
12,5 & 900 & Arenito Bauru seco \\
44,0 & 20 & Arenito Bauru saturado \\
& 650 & Derrame basáltico \\
\hline
\end{tabular}

Nas proximidades do ponto de medida, uma cisterna apresentava na ocasião, o nível d'água a uma profundidade de cerca $15 \mathrm{~m}$. Em um ponto situado a aproximadamente $500 \mathrm{~m}$ do ponto da sondagem elétrica, foi executada uma sondagem rotativa que atingiu a camada basáltica a uma profundidade de $60 \mathrm{~m}$, o que corresponde muito bem à profundidade obtida pela interpretação da curva. 
ER-23 Essa sondagem foi executada na altura do $\mathrm{km} 255$ da rodovia que liga São Carlos a Araraquara. A interpretação da curva é a seguinte:

\begin{tabular}{ccl}
\hline Espessura, $\mathrm{m}$ & Resistividade, $\Omega \cdot \mathrm{m}$ & \multicolumn{1}{c}{ Litologia } \\
\hline \hline 1,4 & 180 & Solo argiloso (basalto alterado) \\
1,6 & 700 & Basalto fresco \\
7,0 & 100 & Arenito Botucatu \\
30,0 & 30 & Arenito Botucatu saturado \\
& 700 & Derrame basáltico \\
\hline
\end{tabular}

Por meio de um altímetro, foi possível verificar que o contato aflorante entre o derrame basáltico e o arenito situa-se $3 \mathrm{~m}$ abaixo do ponto onde foi executada a sondagem elétrica. Em uma cisterna localizada a cerca de $300 \mathrm{~m}$ desse ponto, verificou-se que o nível freático situa-se $10 \mathrm{~m}$ abaixo da cota do ponto da sondagem ER-23.

ER-24 Executada próxima da SE-23 (veja a Fig. 8). A interpretação da curva indica a presença de uma camada de arenito Botucatu com a espessura de $41 \mathrm{~m}$. Sob o Arenito Botucatu encontra-se um derrame basáltico com a espessura de $44 \mathrm{~m}$ seguidos novamente por arenito com a espessura de $40 \mathrm{~m}$. Esse arenito repousa sobre outro derrame, que é notado nitidamente em SE-23.

A partir da interpretação das sondagens ER-23 e ER-24, é possível construir-se uma seção geológica identificando as diferentes formações com base no seu valor de resistividade, como mostra a Fig. 8 .
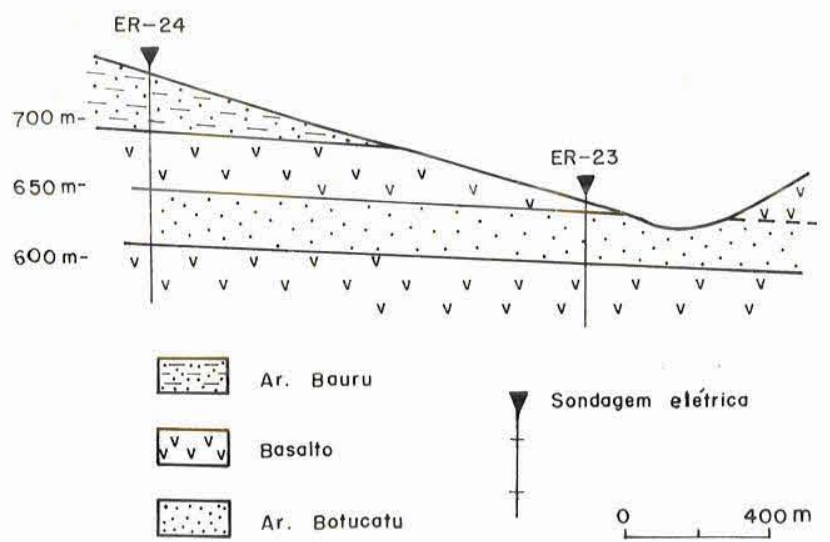

Figura 8 - Seção geológica

ER-9 Sondagem elétrica executada junto à rodovia que passa por Bálsamo. Foi ali realizada por existirem dois poços profundos, um dos quais em fase de perfuração. Nesse poço, foi então executado um perfil de poço a fim de determinar a resistividade real da camada de Arenito Bauru. Com os dados, foi possível interpretar melhor a sondagem elétrica, no que se refere à determinação da profundidade do contato entre o basalto e o arenito sobrejacente. A sua interpretação é a seguinte: 


\begin{tabular}{rcl}
\hline Espessura, $\mathrm{m}$ & Resistividade, $\Omega \cdot \mathrm{m}$ & \multicolumn{1}{c}{ Litologia } \\
\hline \hline 1,1 & 120 & Solo arenoso \\
3,9 & 44 & Arenito Bauru saturado \\
130,0 & 18 & Arenito Bauru saturado \\
& 670 & Derrame basáltico \\
\hline
\end{tabular}

Os dados do perfil de poço executado fornecem uma resistividade real da camada de Arenito Bauru de $19,4 \Omega \cdot \mathrm{m}$, o que corresponde muito bem ao valor obtido quando da execução da sondagem elétrica em virtude de grande espessura da camada de arenito.

CONCLUSÕES a) Grupo Tubarão 1) Por meio de sondagens elétricas é relativamente fácil verificar a continuidade lateral das camadas sedimentares, mesmo em locais onde não se consegue por meio de perfis litológicos de poços próximos.

2) Os sedimentos do Grupo Tubarão possuem uma acentuada gama de variação de resistividades, valores estes que variam de poucas dezenas a milhares de $\Omega \cdot \mathrm{m}$.

3) Próximo a sills de diabásio, a intensidade das correntes telúricas é muito grande, impedindo medidas com espaçamentos entre $M$ e $N$ superiores a $40 \mathrm{~m}$.

4) Parece ser possível, dentro de uma certa margem de erro, prever a vazão específica de um poço, em função da resistividade da camada aqüífera.

b) Formação Botucatu 1) O Arenito Botucatu, quando saturado de água possui uma resistividade da ordem de $30 \Omega \cdot \mathrm{m}$. Quando seco, possui valores de centenas a milhares de $\Omega \cdot \mathrm{m}$, permitindo, portanto, uma fácil determinação do nível estático.

2) Quando a superfície do terreno é formada por areia solta e seca, aparece uma elevada resistência de contato (entre o solo e os elétrodos) chegando a impedir a execução da sondagem elétrica.

c) Derrames basálticos 1) Normalmente é fácil determinar a espessura dos derrames de basalto.

2) A resistividade do basalto, quando este se apresenta sob a forma de vários derrames sobrepostos, causa uma elevada anisotropia elétrica, que se manifesta através de resistividades muito elevadas.

3) Em geral, a intensidade das correntes telúricas é bem reduzida.

4) Como os solos de basalto são relativamente argilosos, a resistência de contato é baixa, da ordem de $700-800 \Omega \cdot \mathrm{m}$.

d) Arenito Bauru 1) A espessura dos sedimentos bem como a profundidade de lençol freático são fáceis de determinar pelas mesmas razões do Arenito Botucatu.

2) Como os Sedimentos Bauru possuem uma certa porcentagem de material argiloso, a resistência de contato é inferior àquela encontrada nos Arenitos Botucatu.

\section{BIBLIOGRAFIA}

BENTZ, A. - 1961 - Lehrbuch der Angewandten Geologie. Ferdinand Enke Verlag, Stuttgart, $1067 \mathrm{pp}$.

DURANTE, A., PANNUTI, E. L. e MEZZALiRA S. - 1965 - Estudos e captações de água subterrânea, no Estado de São Paulo, feitos pelo Instituto Geográfico e Geológico. Secretaria da Agricultura, Inst. Geog. e Geol., Bol. 44, 14 pp., São Paulo

INSTITUTO GEOGRÁFICO E GEOLÓGICO DO ESTADO DE SÃO PAULO - 1963 Mapa Geológico do Estado de São Paulo 